\title{
Reciprocal Teaching with Buddy to Improve Metacognitive Strategies of a High School Student with Reading Comprehension Difficulties
}

\author{
Rizki Mustika ${ }^{\mathrm{a}}$ and Lucia RM Royanto ${ }^{\mathrm{b}^{*}}$
}

${ }^{a}$ Masters and Professional Educational Psychology Program, Department of Educational Psychology, Faculty of Psychology, Universitas Indonesia, Depok, Indonesia; ${ }^{b}$ Department of Educational Psychology, Faculty of Psychology, Universitas Indonesia, Depok, Indonesia

*Corresponding Author:

Lucia RM Royanto

Educational Psychology Department

Faculty of Psychology, Universitas Indonesia

Jl. Lkr. Kampus Raya, Depok, Jawa Barat

Indonesia, 16424

Tel.: +62 217270004

email address: lucia.retno@ui.ac.id 


\title{
Reciprocal Teaching with Buddy to Improve Metacognitive Strategies of High School Students with Reading Comprehension Difficulties
}

\begin{abstract}
Reading is a complicated activity that involves cognitive and metacognitive strategies. Metacognitive strategies can be used to understand a text. Metacognitive strategies can help individuals to regulate their knowledge, manipulate information, and reflect understanding, to capture the meaning of the text. The objective of this research is to examine whether intervention program with reciprocal teaching carried out by a buddy can improve metacognitive strategies used by the student. This research is conducted using single-subject design to a high school student with reading comprehension difficulties. The program consisted of four phases, i.e. preparation, baseline, treatment, and evaluation. During the baseline phase, metacognitive strategies were measured. During the treatment phase, the subject received learning program with reciprocal teaching and buddy reading. His metacognitive strategies were measured afterward. The result showed that there was an improvement in the variety and type of metacognitive strategies used by the subject while reading. This research cannot determine whether the reading difficulties are tackled. However the difficulties to understand are slightly overcome.
\end{abstract}

Keywords: metacognitive strategies, reciprocal teaching, buddy, high school student

\section{Introduction}

Reading is an important activity in human life. By reading, someone can acquire knowledge, develop insight, enrich the mindset, and learn new things. Reading is also important at all levels of education, since elementary school until higher education. At school, reading is the most regular activity that involved in the learning process, and it is undeniable that reading ability is the foundation for students' academic development (Lyon, Shaywitz, \& Shaywitz, cited in Sanford, 2015).

Unfortunately, reading ability becomes a challenge for almost every country. In 2015, the Organization for Economic Co-operation and Development (OECD) conducted a research on reading, science and mathematics, named the Program for International Student Assessment (PISA). The study involved research participants from 72 countries around the world, including Indonesia, and aimed to see the academic performance of 15-year-old students in mathematics, science, and reading. The results showed that on average as many as $20 \%$ of the students in these countries do not meet the minimum standards of reading ability. The results also showed that Indonesia is among the 10 countries with the lowest academic performance, including reading. In reading ability, Indonesia's score is far below average and that means many Indonesian students have difficulties in reading.

The phenomena of reading difficulties can be found in students from all levels of education, however high school students, are the most groups who need help to overcome the reading difficulties (Twomey, 2006). Their reading difficulties can cause many troubles, because the curriculum of secondary school only focuses on mastery the subject, and therefore, reading skills is not taught anymore (Westwood, 2008). In high school, students are assumed to have learned basic reading skills in previous level (Larkin \& Ellis, in Twomey, 2006), so that teachers no longer provide special treatment to help students with reading problems.

The Regulation of the Minister of Education and Culture of the Republic of Indonesia Number 68 and 69 (2013) also indicates that high school students have more complex of core competencies. They are not only expected to master reading materials, but also are required to analyze the information obtained using the knowledge already possessed. With these big demands, high school students who have difficulty in reading will face bigger challenges. To overcome this, students need to have adequate reading skills, especially in reading comprehension. 
According to Underwood (in Novotny \& Grace, 2011) reading comprehension is the most important reading skill possessed by high school students. The students who have good reading comprehension will be able to master the subjects and achieve academic success (Novotny \& Grace, 2011). For high school students in Indonesia, reading comprehension is needed to master lessons and meet the core competencies mentioned previously. By fulfilling core competencies, students can demonstrate good academic performance in schools. According to Block (2004), reading comprehension is an active process supported by thought processes, knowledge, expectations, and reading objectives. It appears that understanding the text need more complex process than just reading.

According to Santrock (2011), to be able to understand the texts, an individual requires metacognitive skills. Flavell, as cited in Papaleontiou-Louca (2008) stated that metacognition is a person's knowledge of his or her cognitive processes. This relates to the individual's skills in regulating his or her thinking activity to use the right strategy in performing a task (Flavell, 1981). Metacognition consists of three factors, namely personal factors, task factors, and strategy (Flavell, as cited in Velzen, 2016). Personal factors relate to personal knowledge of his or her strengths and weaknesses in thinking, task factors relate to personal knowledge of the difficulty level of a task, and the strategy factor is personal knowledge of tactics or the ways to accomplish a task and to achieve a particular goal. Personal factors and personal tasks can be learned individually by individuals, but strategic factors need to be taught so that individuals can use them to deal with specific tasks.

In reading, there are many strategies used, however, the number, type, and the way of using them are different from one student to another (Royanto, 2012). Therefore, the metacognitive strategies used by everyone are different. Royanto (2012) mentioned that in grade 3, there are 16 metacognitive strategies used by individuals when reading. Those include aware-knowing, text evaluating, defining, repeating, asking for information, knowledge evaluating, paraphrasing, verifying, and drawing a conclusion. The sum of strategies and the effectiveness of the strategies used depend on how expert the student in reading. The more expert the students, the more effective strategies they use.

In understanding a text, metacognitive strategies help individuals regulate their knowledge, manipulate information obtained from the text, and reflect understanding, to capture the meaning of the text (Block, 2004). Research conducted by Pressley and Harris (as cited in Clark, 2003) suggested that metacognitive strategies have a positive impact on reading comprehension. Haller, Child, and Walberg (as cited in Clark, 2003) examined further and found that metacognitive strategies can effectively improve reading comprehension. Additionally, Block (2004) stated that the use of metacognitive strategies could improve achievement, motivation, and attitudes toward reading. It is also mentioned that advanced readers usually use metacognitive strategies in reading and comprehension (Block, 2004). Therefore, it can be concluded that by increasing the use of metacognitive strategies, students' reading comprehension skills can be enhanced.

Taylor and Frye (1992), proposed five methods that can help students understand text, imagery, self-questioning, group story mapping, reciprocal teaching, and text look backs. In the imagery method, students are taught to picture an image that represents what they read. In self-questioning students are taught to make their questions about the text. In reciprocal teaching students in groups are taught understanding strategies (ask, clarify, summarize, and predict), then students alternately play a role as a teacher. The text look backs method helps students to answer questions about the text that have been read. Group story mapping is similar to self-questioning method, but in group story mapping students are asked to write answers to questions that have been made on an individual answer sheet.

The five methods proposed by Taylor and Frye (1992), students can build their metacognitive strategies. Imagery keeps students in mind of their previous knowledge and links the information 
received with a representative visualization. Self-questioning and group story mapping lead students to check their understanding. Text look backs help students reflect on understanding and remember what has been read. Reciprocal teaching helps students examine their understanding, overcome failure to understand words or sentences in the text, activate prior knowledge, and motivate students to continue reading activities (Klingner, Vaughn, \& Boardman, 2007). From the description, it appears that reciprocal teaching helps students to use more metacognitive strategies when reading.

Block (2004) stated that reciprocal teaching is an approach that supports the improvement of reading comprehension by involving metacognitive strategies. Reciprocal teaching is a method developed by Brown and Palincsar in 1984 to improve the reading comprehension of high school students (Klingner, Vaughn, \& Boardman, 2007). In its development, reciprocal teaching is more studied by involving elementary school students as participants, such as research conducted by Takala (2006) and Laderer (2015). Both studies showed that reciprocal teaching could improve students' performance in reading comprehension. Research on the effectiveness of reciprocal teaching in high school students was done by Clark in 2003. He gave an intervention program using reciprocal teaching approach to 15 high school students with different level of intelligence. As a result, $90 \%$ of participants stated that the program was beneficial and $40 \%$ of participants said reciprocal teaching improved reading comprehension. However, this research did not measure the metacognitive strategies used,

In reciprocal teaching, there are three important components, namely scaffolding, conversation or discussion, and understanding strategies (Klingner, Vaughn, \& Boardman, 2007). In scaffolding, the individual learns a new skill from a more competent person. The person provides help whose level is adjusted to the individual's progress, which enables him to develop optimally. Assistance is also gradually reduced so that in the end individuals can do the material that is taught independently (empowering). The second component is conversation or discussion. This can add and clarify students' knowledge (Lederer, 2000). This is an important factor in building student cognition (Palincsar, in Lederer, 2000). The next component is four comprehension strategies, which are the heart of the reciprocal teaching approach. The four strategies include asking, clarifying, summarizing, and predicting, and it is a tactic commonly used by proficient readers to understand the text (Klingner, Vaughn, \& Boardman, 2007).

The principle of scaffolding in the reciprocal teaching approach will be used in this buddy reading intervention. According to Block (2004), buddy reading is one of the learning methods that can be used to improve students' reading comprehension. In this method, a more competent friend teaches another friend who has competence below him/her. Teachers classify two students who have different competence levels as "buddies" and undergo a learning program together (Block, 2004). This method is effective for building self-regulation of students in reading to improve reading comprehension (Block, 2004). Also, this method is proven to have many benefits, such as improving self-confidence, ownership, and pride in students, as well as creating a comfortable learning atmosphere (Block, 2004). Buddy reading can also increase students' motivation in reading (Dean, as cited in Manring, 2003), and can involve the students to reading activities (Lai, as cited in Manring, 2003).

Buddy reading method is suitable to be applied in the intervention program for high school students because according to the psychosocial characteristics of adolescents. For teenagers, friends or peers are a source of emotional support and encouragement for a behavioral change (Papalia, Olds, \& Feldman (2009). In adolescence, individuals rely more on friends (Papalia, Olds, \& Feldman, 2009). Great help and influence in the life of adolescents, including in the academic field. Therefore, friends or peers can become a buddy in helping a student with reading comprehension difficulties.

The purpose of this study is to see whether the intervention program with reciprocal teaching and buddy reading approach can increase the use of metacognitive strategies in a grade 10 student with 
reading comprehension difficulties. Not many students in high school level are still having trouble in understanding a text. This study uses a single subject that meets the criteria, i.e., a grade 10 high school male student with the initials A. A is currently 16 years one month and he has difficulty in reading comprehension. A can read fluently, but he does not know how to understand the material being read. This makes $\mathrm{A}$ feels that the reading activity is an unpleasant experience and tends to avoid it. This then adversely affects his academic performance. In reciprocal teaching, A will be trained to use the four strategies (questioning, clarifying, summarizing, and predicting) that can increase the use of metacognitive strategies on A when reading. The reciprocal teaching method will be combined with buddy reading, in which A will be paired with a close friend that is more experienced. Learning with a close friend is expected to create a comfortable learning atmosphere for A.

\section{Methods}

\section{Research Design}

This study used a single-subject experimental design, to be more specific, the single-subject experimental design in the current study was $\mathrm{AB}$ design, which consisted of baseline phase (A) and treatment phase (B). Each phase had to be measured at least three times, to establish a pattern (level or trend) and to determine the stability of the data within a phase. For this reason, the researcher would employ three measurements during the baseline period and also three measurements in the treatment phase.

\section{Participant}

There is one participant in this study, a grade 10 a high school student as the subject and his friend (buddy) who taught him during the program with reciprocal teaching. The subject had difficulties in reading comprehension. He could read fluently, but he did not understand what he read. In other words, he had a lack of ability in reading comprehension.

Meanwhile, the buddy was chosen based on the consideration of the homeroom teacher and the counselor. In detail, the buddy had to have the following characteristics:

a. A person who could understand lessons taught to the student and the process of teaching.

b. An individual who had excellent verbal skills and had expert reader criteria, such as having extensive knowledge and using it to make conclusions. He also comprehended that the purpose of reading was to build understanding, respond to the meaning of words or sentences during reading activities, and possess and apply various vocabulary to understand the reading material.

c. He must be interested in tutoring activities, so he seriously and willingly participated in the program.

d. The buddy agreed to take part in the intervention program.

\section{Instruments}

One text consists of several paragraphs is chosen to be read by the student. The measurement is carried out by using a verbal report, i.e., think aloud method. The subject is asked to tell about what they think after reading a paragraph. After that, the subject is asked to express whatever they think while reading the paragraph, and all the answers are voice recorded. By doing so, there is a little chance of missing any data. During the intervention, the researcher used several tools, as follows:

\section{a. Program Module}

The module was a program implementation guide, containing intervention sessions, session objectives, steps in each session, indicators determining the success of the sessions, tools, duration, and where the sessions were implemented.

The program took for 6-8 days with a total number of learning sessions of 3-5 times (adjusted to subject development). The number of sessions was determined by considering the 
characteristics of the subject who was a high school student. The subject was predicted to master the four strategies of reading comprehension in 3-5 times of teaching activity. A short brief was given to the buddy, thus he understood what was expected towards him. The sum of activities was based on the previous research on reciprocal teaching, about ten learning sessions (Takala, 2006) to 13-15 learning sessions (Laderer, 2015).

b. Material

The materials consisted of a Think Aloud protocol ( 1 text), a text for the Buddy to prepare him on the four comprehension strategies), 13 texts to be used in the process. For the measurement, there are three texts for baseline and three texts for treatment, and also three texts for the learning sessions. The think aloud protocol was used for measuring the metacognitive strategies applied by the participant. All the responses of the participants will be recorded and categorized into metacognitive strategies used by previous research.

All the materials are in Bahasa Indonesia (Indonesian language) and from grade 10 high school textbooks. Selected texts were derived from common themes that are familiar to high school students, such as about tours, culinary, traffic, television shows, university life, and health. These common themes were selected to make the text appropriate and relevant to the participants (subject and Buddy). The material for Buddy preparation was the text regarding four strategies of reading comprehension which was written in a simple language. The material for measurement was taken from the general encyclopedia of animals. This theme was chosen for two reasons. First, the student has a great interest in literature about the animal, so the theme was expected to bring up his eagerness to read. Second, literature about animal usually have unpretentious structure, which allowed the subject to comprehend the text and tell the researcher what he thinks. To determine the degree of difficulties of the six texts, an expert judgment from a Bahasa Indonesia teacher was obtained (expert judgment).

c. Media

Media consisted of tools used by the researcher to explain material (details of the program and the explanation of the understanding strategies). Media consisted of flip chart paper, some metaplans, and colourful post-it papers. The researcher explained the material while pitching the papers having been written, to shorten the duration of explanation and make the participants easy to understand the material.

\section{d. Parent's Consent, Informed Consent, and Learning Contract}

The consent form, informed consent, and learning contract contained specific intervention of the program. They were given to the participant, the buddy, and the parents.

\section{Procedure}

The intervention program was divided into four phases, namely preparation, baseline, treatment, and evaluation. Activities undertaken in these phases can be seen in the following chart:

\footnotetext{
Preparation

1. Participant Preparation (Program Explanation, Parent's Consent, Informed Consent, Learning)

2. Subject preparation (Think Aloud exercise)

3. Buddy preparation (Reciprocal Teaching exercise)
}

\begin{tabular}{|l|l|l|}
\hline Baseline Measurement & $\begin{array}{l}\text { Treatment Phase } \\
\text { Learning sessions of } \\
\text { Reciprocal Teaching } \\
\text { with the buddy (3 } \\
\text { times) } \\
\text { Measurement (3 } \\
\text { times) }\end{array}$ & Evaluation \\
times) & 2. Evaluation & \\
\hline
\end{tabular}

Figure 1. The Intervention Program Design 
At the baseline phase, the researcher prepared both the participant and the buddy. It began with explaining the details of the program, asking for parents' consent for their children's participation in the program, and accepting the informed consent and the learning contracts. The researcher then taught the buddy and the participant separately about their roles.

1. The participant was practiced to think aloud thus the participant would be used in the measurement processes. This measurement was carried out to measure the metacognitive strategies used by the participant.

2. The buddy was trained to practice the reciprocal teaching for the learning sessions.

3.

After the participant understood the Think Aloud procedure, the baseline measurement began.

In the treatment phase, the buddy led the learning process to the participant by applying the four strategies in reading (questioning, clarifying, summarizing, and predicting). All the processes were using conversations and discussions. At the end of each learning session, the researcher did measurements with think-aloud protocols that had been prepared in advance. Finally, the participant and the buddy evaluated the program and themselves for the qualitative feedback.

\section{Results}

The measurements are based on the metacognitive strategies used by the participant. The measurement results can be seen in the following table:

Table 1.

Measurement of Metacognitive Strategies

\begin{tabular}{lcccccc}
\hline & \multicolumn{3}{c}{ Baseline } & \multicolumn{3}{c}{ Treatment } \\
\cline { 2 - 7 } & 1 & 2 & 3 & 1 & 2 & 3 \\
\hline $\begin{array}{l}\text { Number of } \\
\text { metacognitive } \\
\text { strategies }\end{array}$ & 19 & 24 & 18 & 45 & 43 & 35 \\
\hline
\end{tabular}

The results of these measurements are demonstrated using visual inspection techniques as follows:

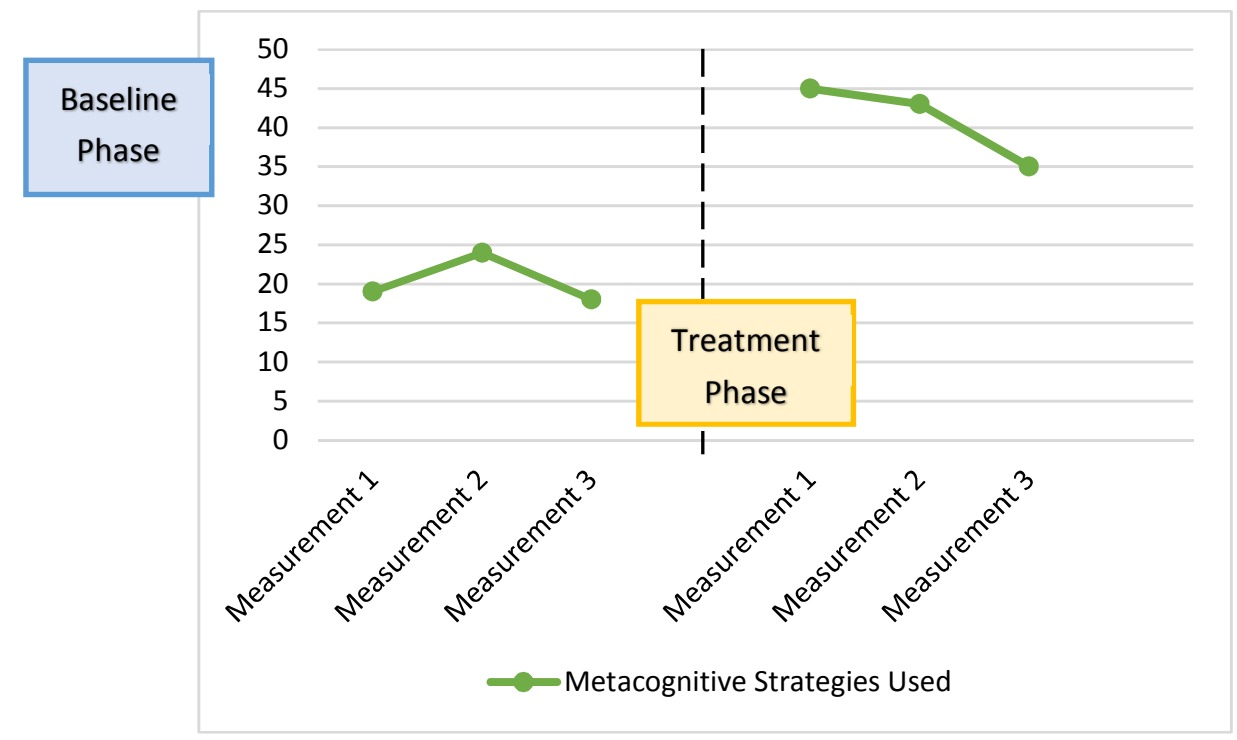

Figure 2. Visual Inspection of Metacognitive Strategies Used

Based on the graph above, in overall there is an increasing number of metacognitive strategies used by the subject from the baseline phase to the treatment phase. The increase can be said meaningful because there is an average change in the number of metacognitive strategies the subject used, from 20.3 in the baseline phase to 41.0 in the treatment phase. The increase occurred at $101.9 \%$. Also, the graph also shows a sudden rise in levels from the baseline phase to the treatment phase 
(immediate change in level). However, there is a decline in the third measurement, both in baseline and treatment phase.

From the think-aloud process, all the responses used by the participant are transcribed and categorized into the metacognitive strategies. There are sixteen metacognitive strategies in the category, organized by their effectiveness, from number 1 as the least effective strategy, to the number 16 as the most effective strategy in reading. The following table is presented based on that strategy classification:

Table 2.

Use of Metacognitive Strategies Subject

\begin{tabular}{|c|c|c|c|c|c|c|c|c|c|c|c|c|c|}
\hline \multirow{3}{*}{ No } & \multirow{3}{*}{$\begin{array}{c}\text { Type of } \\
\text { Metacognitive } \\
\text { Strategies }\end{array}$} & \multicolumn{12}{|c|}{ Frequency and Percentage of Metacognitive Strategies Used } \\
\hline & & \multicolumn{6}{|c|}{ Baseline } & \multicolumn{6}{|c|}{ Treatment } \\
\hline & & \multicolumn{2}{|c|}{1} & \multicolumn{2}{|c|}{2} & \multicolumn{2}{|r|}{3} & \multicolumn{2}{|c|}{1} & \multicolumn{2}{|c|}{2} & \multicolumn{2}{|r|}{3} \\
\hline 1 & Aware-Knowing & 17 & $89 \%$ & 18 & $75 \%$ & 18 & $100 \%$ & 3 & $7 \%$ & 5 & $12 \%$ & 4 & $11 \%$ \\
\hline 2 & Text Evaluating & - & - & 2 & $8 \%$ & - & - & 1 & $2 \%$ & 1 & $2 \%$ & - & - \\
\hline 3 & Defining & 1 & $5 \%$ & 2 & $8 \%$ & - & - & 1 & $2 \%$ & 6 & $14 \%$ & 5 & $14 \%$ \\
\hline 4 & Reread & - & - & - & - & - & - & 1 & $2 \%$ & - & - & - & - \\
\hline 5 & Repeating & - & - & - & - & - & - & - & - & - & - & - & - \\
\hline 6 & Asking Explicitly & 1 & $5 \%$ & 2 & $8 \%$ & - & - & 18 & $40 \%$ & 14 & $33 \%$ & 12 & $34 \%$ \\
\hline 7 & Ask Information & - & - & - & - & - & - & 3 & $7 \%$ & 5 & $12 \%$ & 1 & $3 \%$ \\
\hline 8 & $\begin{array}{l}\text { Knowledge } \\
\text { Evaluation }\end{array}$ & - & - & - & - & - & - & 1 & $2 \%$ & - & - & - & - \\
\hline 9 & Lack of Problem & - & - & - & - & - & - & - & - & - & - & 1 & $3 \%$ \\
\hline 10 & Ask Hypothesis & - & - & - & - & - & - & - & - & 2 & $5 \%$ & 1 & $3 \%$ \\
\hline 11 & Paraphrasing & - & - & - & - & - & - & - & - & - & - & - & - \\
\hline 12 & New Information & - & - & - & - & - & - & 1 & $2 \%$ & - & - & - & - \\
\hline 13 & Verification & - & - & - & - & - & - & - & - & - & - & - & - \\
\hline 14 & Conclusion & - & - & - & - & - & - & 13 & $29 \%$ & 10 & $23 \%$ & 10 & $30 \%$ \\
\hline 15 & Elaboration & - & - & - & - & - & - & 3 & $7 \%$ & - & - & 1 & $3 \%$ \\
\hline \multirow[t]{2}{*}{16} & Anticipation & - & - & - & - & - & - & - & - & - & - & - & - \\
\hline & Total & 19 & $100 \%$ & 24 & $100 \%$ & 18 & $100 \%$ & 45 & $100 \%$ & 43 & $100 \%$ & 35 & $100 \%$ \\
\hline
\end{tabular}

From the table above, it appears that there has been a change in the use of metacognitive strategies on the subject. In the baseline phase, the subject used only four types of metacognitive strategies, such as the aware-knowing strategy, text evaluating, defining and asking explicitly. Those strategies are not effective in helping the participant to understand a text. In the treatment phase, the participant uses more diverse strategies. Thus from using only four strategies, the participant uses 12 strategies. In addition to the four strategies already used in the baseline phase, the participant also uses re-reading strategies, asking explicitly, ask information, knowledge evaluation, lack of a problem, ask hypothesis, new information, conclusion, and elaboration.

Besides the participant use of more diverse types of strategies in the treatment phase, he also uses more effective metacognitive strategies. In the baseline phase, subject uses the most aware-knowing strategy $(75 \%-100 \%)$ which is the lowest effective strategy. During the treatment phase, mostly he used asking explicitly strategy $(33 \%-40 \%)$ that had a higher level of effectiveness. In the treatment phase, he used fewer aware-knowing strategy, like no more than $12 \%$. The participant even begins to use elaboration and conclusion strategies that are categorized in the 3 most effective metacognitive strategies. In other words, in the treatment phase the use of less effective strategies decreases and the use of more effective strategies increases.

Based on the result of the research, there is an improvement of metacognitive strategies used. There is an obvious improvement, as visual inspection shows a change in the average number of metacognitive strategies the participant used when reading, as well as sudden graphic level changes. In addition to the number, the provision of interventions also increases the variety of strategies and the level of effectiveness of the strategies the participant use. So it can be concluded that the 
intervention program using reciprocal teaching and buddy reading can effectively increase the use of metacognitive strategies a student with difficulty in reading comprehension.

\section{Discussion}

The reciprocal by a buddy seems to help a student to use metacognitive strategies in reading. Reciprocal teaching has three important components, namely scaffolding, conversation or discussion, and understanding strategies (Klingner, Vaughn, \& Boardman, 2007). These three components appear to systematically increase the use of metacognitive strategies of the participant. Previously, the participant read with little strategies, thus he had difficulties in understanding a text. However, with little guidance from a buddy based on reciprocal teaching, he started to develop strategies for reading. Such guidance or assistance may be an encouragement, direction, giving examples, explanation, directing questions, discussion, participation, and so on. The provision of guidance or assistance is helping the improvement of students' abilities and gradually reduced their difficulties (Klingner, Vaughn, \& Boardman, 2007).

In this intervention program, the participant were accompanied by a more competent buddy when performing reading activities. During the learning process, the buddy provides assistance in the form of discussion based on some activities such as questioning, clarifying, summarizing and predicting. During the sessions the buddy also give encouragement, guidance, examples, explanations, and directions through the conversation and discussion. When the participant showed improvement in reading, the buddy reduced the help given. The buddy slowly released the responsibility to the participant, therefore the participant was more confident in reading, especially in using strategies in reading.

In reciprocal teaching, conversations and discussions giving the opportunity to the participant to evaluate and improve their understanding (Gauvain, as cited in Santrock, 2011). In the search for mutual understanding, the participant's thinking evolves when he listens to the thoughts of others, in this case, the buddy, (Gauvain, in Santrock, 2011). From there the participant can observe the buddy, evaluate his skills, and imitate the strategies applied by the buddy. Through this mechanism, internalization takes place within the individual (Santrock, 2011). Knowledge initially is external (interdental) gradually internalized by students into the mind (instrumental).

In the reciprocal teaching approach, students learn to use four comprehension strategies, which are questioning, clarifying, summarizing, and predicting. These four strategies are tactics commonly used by advanced readers to get understanding (Klingner, Vaughn, \& Boardman, 2007). The strategies seem to effectively increase the strategies used by the participant, in quantity, types, and level of effectiveness. Therefore, it can be said that the comprehension strategies taught can be the lighter the emergence of other strategies.

As mentioned above, buddy acts as a scaffold in this intervention program. In practice, the existence of buddy seems to have other positive effects. As stated by the participants in the evaluation session, the learning activities conducted with close friends are considered very useful and enjoyable. The subject looks more relaxed and free; it can be seen from the way they interact. The pleasant atmosphere makes the participant more motivated to read.

The characteristics of buddy greatly determine the success of the program. In this program, the buddy meets the characteristics of the expert reader, which has extensive knowledge and vocabulary and understands that the purpose of reading is to understand it. Buddy also has an interest in teaching activities and has a desire to be able to teach children. This is what makes the buddy suitable to perform its role during the intervention program. Also, there are other positive things that buddies have, that is having the ability to use metacognitive strategies with a high level of effectiveness. In the buddy preparation session, the researcher examined the metacognitive strategies used by a buddy, and the results were "verification," "elaboration," "conclusion," and 
"anticipation" strategy. These four strategies are the most effective metacognitive strategies. This good skill helped in increasing the use of more effective metacognitive strategies in the subject.

This study has limitations related to the program preparation, program implementation, and results in analysis. Related to the preparation of the program, the time available is limited so that the researcher cannot ask the Indonesian language teacher to do an expert judgment. Expert judgment is required, to ensure that materials used for measurement are at the same in difficulty level. It can control the measurement result is as the treatment given, not because of the unequal reading difficulty level. The drop of the third measurement can be caused by the unequal of reading difficulty level of the text.

In the implementation, the researcher has no prescribing procedure for attendance, which makes the participants do not feel obliged to come at a certain hour. This impacts on the participant's responsibility related to the sustainability of the program. In the implementation of this intervention program, researcher gives one evaluation session at the end of the program. From the evaluation, the researcher knows how the subject and buddy opinions about the program, as well as how their comprehension is. If the researcher conducts an evaluation session at the end of each meeting, the researcher will know the program participants' opinions and the insights gained from each meeting. This information can be used to improve program implementation the next day, and conduct program analysis more deeply. In the analysis process, the researcher analyzed the transcripts without inter-rater agreement, which can cause bias. In the next research, it is suggested to do an inter-rater analysis to reduce subjectivity and to enhance the reliability of the research.

\section{References}

Block, C. (2004). Teaching comprehension: The comprehension process approach. Boston: Pearson Education

Minister of Education and Culture of the Republic of Indonesia. (2013). The Regulation of the Minister of Education and Culture of the Republic of Indonesia Number 68. ”. Access on June 26, 2017. Downloaded from http://eadm.dindik.jatimprov.go.id/upload/hukum/salinan-permendikbud-no-45-tahun-2015.pdf

Minister of Education and Culture of the Republic of Indonesia. (2013). The Regulation of the Minister of Education and Culture of the Republic of Indonesia Number 69. ”. Accsess on April 23, 2017. Downloaded from https://jdih.surabaya.go.id/pdfdoc/permen_9.pdf

Flavell, J. H. (1981). Social cognitive development: frontiers and possible futures. London: Cambridge Press

Gravetter, F.J. \& Forzano, L.B. (2009). Research methods for the behavioral sciences ( $3^{\text {rd }}$ ed.). Belmont, CA: Wadsworth

Klingner, J. K., Vaughn, S., Boardman, A. (2007). Teaching reading comprehension to students with learning difficulties. New York: The Guilford Press

Latipun. (2011). Psikologi eksperimen. Malang: UMM Press

Lederer, J. M. (2000). Reciprocal teaching of social studies in inclusive elementary classroom. Journal of Learning Disabilities, $33(1), 91-106$

Manring, M. S. (2003). "Book buddy programs: providing students with improved reading and social skills”. Missouri: University of Central Missouri

Novotny, R. \& Grace, K. (2011). Reading comprehension in the secondary classroom. Mankato: Minnesota State University

OECD. (2016). PISA 2015 assessment and analytical framework: mathematics, reading, science problem solving and financial literacy. ”. OECD Publishing

Papalia, D., Olds, S. W., \& Feldman, R. D. (2009). Human development (11 $1^{\text {th }}$ ed.). New York: McGraw Hill

Royanto, L. R. M. (2012). The effect of an intervention program based on scaffolding to improve metacognitive strategies in reading: A study of year 3 elementary school students in Jakarta. Procedia Social and Behavioral Sciences

Sanford, K. L. (2015). "Factors that Affect the Reading Comprehension of Secondary Students with Disabilities". Doctoral Dissertations. San Francisco: The University of San Francisco

Santrock, J.W. (2011). Educational psychology (5 ${ }^{\text {th }}$ ed.). New York: Mc-Graw Hill Companies, Inc

Takala, M. (2006). The effects of reciprocal teaching on reading comprehension in mainstream and special (SLI) education. Scandinavian Journal of Educational, 50(5), 559-576, DOI: 10.1080/00313830600953824

Taylor, B. M., \& Frye, B. J. (1992). Comprehension strategy instruction in the intermediate grades. Reading Research and Instruction, 32(1), 39-48

Twomey, E. (2006). Linking learning theories and learning difficulties. Australian Journal of Learning Disabilities, 11(2), 93-98, DOI: $10.1080 / 19404150609546812$

Westwood, P. (2008). What teachers need to know about learning difficulties? Victoria: Acer press 